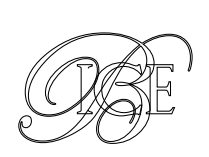

\title{
LA PROPIEDAD INTELECTUAL COMO HERRAMIENTA DE DESARROLLO ECONÓMICO, SOCIAL Y CULTURAL
}

El objeto de este artículo es poner en valor la creciente aportación de las industrias culturales y creativas a la economía española, y especialmente mostrar cómo la vigencia de un elevado nivel de protección de los derechos de propiedad intelectual (derechos de autor y derechos conexos), tal como el que prevé nuestro derecho por incorporación de los estándares derivados del ordenamiento jurídico internacional y de la Unión Europea (estándares en alguno de los cuales España ha sido pionera en la última década), es una herramienta esencial en las economías en las que la sociedad de la información es un activo clave para la creación de riqueza y puestos de trabajo. Un elevado nivel de protección de los derechos de propiedad intelectual acelera el círculo virtuoso en el que el desarrollo económico, empresarial, social y cultural se alimentan mutuamente.

Palabras clave: derechos de autor, industrias culturales, transformación digital.

Clasificación JEL: D23, D51, K11, K21, O34.

\section{Las industrias culturales y creativas en España}

Las industrias culturales y creativas tienen un valor indispensable para la sociedad y son importantes generadoras de riqueza y empleo. En España, la participación cultural de la población antes de la pandemia de la COVID-19 mostraba elevados niveles en ciertos indicadores culturales y la contribución de la cultura al PIB había venido creciendo desde 2013 (la industria cultural representaba en 2019 el 3,2\%

\footnotetext{
* Subdirector General de Propiedad Intelectual. Dirección General de Industrias Culturales, Propiedad Intelectual y Cooperación. Ministerio de Cultura y Deporte.

Versión de junio de 2021.

DOI: https:/doi.org/10.32796/bice.2021.3137.7258
}

del PIB en España y proporcionaba empleo a 710.200 personas, lo que representaba un $3,6 \%$ del empleo total del país). Sin embargo, a pesar de estos datos, el sector adolece de ciertas fragilidades estructurales que le han impedido desarrollar todo su potencial, habiendo sido además un sector fuertemente golpeado por la pandemia.

También de acuerdo con la Cuenta Satélite de la Cultura en España (CSCE), el conjunto de actividades vinculadas con la propiedad intelectual supuso para España un 3,4\% del PIB (producto interior bruto) y un 3,5\% del VAB (vaIor añadido bruto) de 2018, siendo claramente un sector de futuro.

En términos comparativos, el peso del VAB (2018) del conjunto de actividades $\triangleright$ 
vinculadas con la propiedad intelectual es similar al de la agricultura $(3,1 \%)$ y superior al de la industria de alimentación, fabricación de bebidas y tabacos $(2,3 \%)$, la industria química $(0,8 \%)$ o las telecomunicaciones $(1,4 \%)$. Estos resultados ponen de manifiesto que las actividades vinculadas con la propiedad intelectual tienen un peso muy significativo en la economía española.

Tras la reciente crisis desencadenada por la pandemia de la COVID-19, España se enfrenta al desafío de promover la recuperación de este sector económico, que es claramente competitivo por el empleo de una lengua de comunicación internacional, el castellano, con un mercado global de más de 500 millones de personas que consumen los productos de las industrias españolas del libro, la música, el cine o los videojuegos, y por estar formado por industrias, en algunos casos, como la del libro, con cinco siglos de tradición, y que no sería posible crear y consolidar de un día para otro.

Esa recuperación pasa por hacer frente a una serie de desafíos que deben abordarse para fomentar la competitividad, la dinamización y la cohesión territorial del ecosistema cultural español como son el crecimiento, la innovación, la internacionalización, la formación o una verdadera transformación digital. Todos ellos están vinculados a la articulación de una política de defensa y protección del activo jurídico que permite a estas empresas consolidarse y crecer: los derechos de propiedad intelectual, que establecen una protección, en forma de goce y ejercicio de derechos o facultades, a los creadores de obras originales literarias, artísticas o científicas cuando se utiliza o explota su creación.

La participación cultural de la población mostraba antes de la pandemia actual elevados indicadores anuales en actividades culturales como escuchar música, leer e ir al cine, con tasas del $87,2 \%$, el $65,8 \%$ y el $57,8 \%$, respectivamente. Estas actividades eran seguidas en intensidad por la visita a monumentos, que realizaba cada año el 49,3\% de la población, la asistencia a museos o exposiciones, 40,5\% y $29,8 \%$, respectivamente, o la asistencia o acceso por internet a bibliotecas, $26,8 \%$. Cada año, el $46,8 \%$ de la población asistía a espectáculos en directo de artes escénicas o musicales.

A pesar de estos datos, de las $127.581 \mathrm{em}$ presas que existían antes de la pandemia en el ámbito de las industrias culturales y creativas, cifra que suponía el $4 \%$ del conjunto de empresas españolas, el $67,1 \%$ no tenía ningún asalariado, un $26,7 \%$ eran empresas pequeñas (entre 1 y 5 empleados), un $6 \%$ eran medianas (entre 6 y 49 asalariados) y tan solo un $0,5 \%$ daba empleo a más de cincuenta personas. La mayor parte de ellas, el $85 \%$, se dedicaba a actividades de la industria o los servicios, tales como actividades de edición, de bibliotecas, archivos, museos, cinematográfica, de vídeo, de radio y televisión, o las artísticas y de espectáculos, entre otras, y el $15 \%$ restante, a actividades vinculadas al comercio o alquiler de bienes culturales.

Contra la superación de los citados desafíos se ha mostrado una serie de carencias en el ámbito legislativo que deben ser abordadas con el fin de mejorar el marco regulatorio de la cadena de valor artística, literaria y científica, que va desde la protección de la propiedad intelectual hasta los derechos de los propios artistas. Estas carencias deberán resolverse mediante una correcta transposición de las directivas europeas aprobadas en 2019 en el marco del Mercado Único Digital ${ }^{1}$.

1 Directiva (UE) 2019/789, del Parlamento Europeo y del Consejo, de 17 de abril de 2019, por la que se establecen normas sobre el ejercicio de los derechos de autor y derechos afines aplicables a determinadas 
A su vez, la rápida evolución que están experimentando los usos y usuarios de las obras y prestaciones protegidas por derechos de propiedad intelectual y, por tanto, la necesidad de acomodar la protección y promoción de la propiedad intelectual a las exigencias propias de la sociedad de la información actual vienen exigiendo el refuerzo de los derechos de propiedad intelectual que ha sido incluido dentro del Componente 24 del Plan de Recuperación, Transformación y Resiliencia, dedicado a la revalorización de las industrias culturales.

\section{La propiedad intelectual (derechos de autor y derechos conexos)}

\subsection{Base jurídica nacional e internacional}

Según los instrumentos jurídicos vigentes en esta materia en el ámbito internacional (principalmente el Convenio de Berna de 1886, para la Protección de las Obras Literarias y Artísticas), europeo (directivas y reglamentos de la Unión Europea aprobados a partir de la Directiva 2001/29/CE, del Parlamento Europeo y del Consejo, de 22 de mayo de 2001, relativa a la armonización de determinados aspectos de los derechos de autor y derechos afines a los derechos de autor en la sociedad de la información, y que derivan de la creación de un mercado interior y la instauración de un sistema que garantice que la competencia dentro del mercado interior no sea falseada previstas en el Tratado constitutivo de la Comunidad Europea) y nacional (texto refundido de la Ley de Propiedad Intelectual, aprobado por Real Decreto

transmisiones en línea de los organismos de radiodifusión y a las retransmisiones de programas de radio y televisión, y Directiva (UE) 2019/790, del Parlamento Europeo y del Consejo, de 17 de abril de 2019, sobre los derechos de autor y derechos afines en el mercado único digital.
Legislativo 1/1996, de 12 de abril -TRLPI-), la propiedad privada inmaterial que en España conocemos como propiedad intelectual y en la mayor parte de los ordenamientos como derechos de autor y derechos conexos:

- Reconoce protección, en forma de goce y ejercicio de derechos o facultades, a los creadores de obras originales literarias, artísticas o científicas cuando se utiliza o explota su creación.

- Puede consistir en la exclusividad para autorizar esa utilización o explotación, habitualmente a cambio de una compensación económica que incentiva la creación de nuevas obras, también en los nuevos modelos de difusión que internet ofrece.

- Está sujeta a un plazo de protección concreto: las obras que dejan de estar sujetas a esta protección, por el transcurso de un plazo legal (por ejemplo, desde el fallecimiento del autor o desde la fecha de fijación o difusión de una interpretación), pasan a formar parte del dominio público.

\subsection{Objeto del derecho de autor}

Son obras protegidas, objeto de derecho de autor (producto de la actividad de los creadores: literatos, compositores, letristas, autores de obras cinematográficas, dibujantes, pintores, fotógrafos, etc.), las siguientes creaciones cuando reúnen el requisito de la originalidad, según el Convenio de Berna de 1886, para la Protección de las Obras Literarias y Artísticas, trasladado al artículo 10 del TRLPI:

- Libros, folletos y otros escritos, conferencias, alocuciones, sermones. 
- Obras dramáticas o dramático-musicales, obras coreográficas y pantomimas.

- Composiciones musicales con o sin letra.

- Obras cinematográficas y audiovisuales.

- Obras de dibujo, pintura, arquitectura, escultura, grabado, litografía.

- Obras fotográficas o análogas.

- Obras de artes aplicadas, ilustraciones, mapas, planos y obras tridimensionales sobre geografía, topografía, arquitectura o ciencias.

- Sin perjuicio de los derechos del autor de la obra original, las traducciones, adaptaciones, arreglos musicales y demás transformaciones de una obra.

- Las colecciones de obras, las enciclopedias y antologías, sin perjuicio de los derechos de los autores de cada una de las obras que las componen.

Desde el Convenio de Berna de 1886, otros instrumentos jurídicos internacionales o nacionales han incluido bajo esta protección otro tipo de obras, como es el caso de los programas informáticos.

\subsection{Titulares de derechos conexos o afines}

También con posterioridad al Convenio de Berna de 1886, otros instrumentos jurídicos internacionales o nacionales han acuñado formas de protección afines al derecho de autor para otros partícipes imprescindibles en el hecho cultural y en el desenvolvimiento de las industrias culturales y creativas tales como los siguientes:

- Artistas, intérpretes y ejecutantes (tanto en obras fonográficas como audiovisuales).
- Productores de grabaciones sonoras (también denominadas fonogramas) y audiovisuales (cinematográficas, etc.).

- Organismos de radiodifusión (radios y televisiones).

\subsection{Derechos protegidos}

Corresponde al titular de los derechos de propiedad intelectual el ejercicio exclusivo de los derechos de explotación de su obra en cualquier forma y, en especial, las siguientes formas de utilización, que no pueden ser realizadas sin su autorización, salvo en los casos previstos legalmente en el derecho del territorio en que tiene lugar esa utilización (el derecho de propiedad intelectual es eminentemente territorial):

- La reproducción de la obra de varias formas, como las publicaciones impresas y las grabaciones sonoras.

- La distribución de ejemplares de la obra, incluyendo el préstamo de esta en un establecimiento público.

- La interpretación o ejecución públicas de la obra, la radiodifusión o la comunicación al público de la obra por otros medios.

- La traducción de la obra a otros idiomas, la adaptación de la obra, como en el caso de una novela adaptada para un guion, y otras formas de transformación de la obra.

- Los derechos morales (que, a diferencia de los citados derechos de explotación, son irrenunciables e inalienables, no estando sujetos a un plazo de protección concreto) sobre la obra, como reivindicar su atribución u oponerse a cualquier deformación, modificación o menoscabo. 


\subsection{Límites y excepciones}

Al igual que otras formas de propiedad privada, la propiedad intelectual debe cumplir con una función social y puede ser limitada o excepcionada en base al interés público que conforman otros derechos y libertades. Algunos ejemplos de límites y excepciones a esta protección previstos en el ordenamiento jurídico español, y que en ocasiones deberán dar lugar a una compensación a los autores y otros titulares de derechos de propiedad intelectual, son:

- La reproducción para uso privado.

- Las citas extraídas de obras protegidas, a condición de que la fuente de la cita y el nombre del autor sean mencionados y que esa utilización se ajuste a las prácticas honestas (derecho de cita).

- La utilización de obras con fines docentes (derecho de ilustración de la enseñanza).

- La utilización de obras a los fines de la información periodística.

- El acceso a la cultura de las personas con discapacidad.

\subsection{Situación actual}

Asistimos a enormes cambios en la realidad en torno a la propiedad intelectual, operados por las nuevas tecnologías, que están provocando la generalización de la Cultura en Red, la interacción de usuarios y titulares de derechos de propiedad intelectual en el entorno digital, y un cambio de paradigma respecto a la posibilidad de reproducir, distribuir, comunicar al público o transformar contenidos. Todo ello tiene como consecuencias:
- Cambios en los hábitos de consumo de contenidos culturales: adaptación para incrementar la oferta legal, y cambios en los instrumentos de protección/garantía de los derechos de propiedad intelectual que deben adaptarse para mantener el mismo elevado nivel de protección.

- Cambios en los límites y excepciones a los derechos de propiedad intelectual (nuevo equilibrio entre derechos, límites y excepciones, y remuneración/compensación en su caso).

- Posibilidades de mejora de la gestión, con mayor transparencia y control, y nuevos sistemas de resolución de los conflictos, todo lo cual no debería sino facilitar la recaudación correspondiente a la explotación de derechos de propiedad intelectual y el equitativo reparto de esta recaudación entre los titulares de derechos.

\section{Propiedad intelectual como activo económico}

\subsection{Titularidad, ejercicio y cesión del derecho de autor}

Como en todo mercado, el de la propiedad intelectual se articula en base a la relación entre quienes producen dicho activo económico, quienes lo utilizan o consumen, y quienes intermedian en el mercado; triángulo económico que en el mercado de la cultura se basa en una cesión ágil y comprensible, dotada de seguridad jurídica, de los derechos de propiedad intelectual.

La legislación vigente en materia de propiedad intelectual regula detalladamente la $\triangle$ 
cesión de derechos de autor para facilitar esa transmisión como activo en el sector económico de las industrias culturales y creativas, exigiendo su formalización escrita, previendo los casos de nulidad de la misma (obras que pueda crear el autor en el futuro, estipulaciones por las que el autor se comprometa a no crear alguna obra en el futuro, modalidades de utilización o medios de difusión inexistentes o desconocidos al tiempo de la cesión), regulando su posible remuneración proporcional y a tanto alzado, la eventual acción de revisión, etc.

Es importante mencionar la cuestión de la transmisión de los derechos del autor asalariado: la transmisión al empleador de los derechos de explotación de la obra creada en virtud de una relación laboral o funcionarial se rige por lo pactado en el contrato (debiendo este realizarse por escrito) o lo previsto en el Estatuto de la Función Pública. A falta de pacto escrito o previsión legal, se presume que los derechos de explotación han sido cedidos en exclusiva y con el alcance necesario para el ejercicio de la actividad habitual del cesionario en el momento de la entrega de la obra realizada en virtud de dicha relación laboral o funcionarial.

En todo caso, debe tenerse en cuenta, en relación con la cesión del derecho de autor por su titular:

- Una cesión es el traspaso de un derecho de propiedad. La persona a la que hayan sido cedidos los derechos pasa a ser el nuevo propietario o titular del derecho de propiedad intelectual cedido.

- Los titulares originarios de un derecho de propiedad intelectual pueden ceder los derechos patrimoniales sobre sus obras a individuos o empresas que tengan mayores posibilidades de comercializar las obras, y ello a cambio de la debida retribución. Esta es una de las claves del círculo de actividad económica y creación de riqueza y puestos de trabajo que puede construirse sobre la base de los derechos de propiedad intelectual.

\subsection{Defensa, por el titular, de sus derechos de propiedad intelectual}

De poco serviría la regulación del ejercicio y cesión de los derechos de propiedad intelectual si el legislador no previera igualmente un conjunto de medidas de observancia de estos.

Una política de respeto u observancia de los derechos de propiedad intelectual debe incluir la regulación de las vías civil (permitiendo que los órganos jurisdiccionales de lo civil y mercantil realicen todas las diligencias previas de investigación que resulten necesarias, incluyendo su adaptación al ámbito de las infracciones en línea), penal (contando con un tipo penal puesto al día, que no resulte obsoleto) y administrativa (regulando un procedimiento administrativo ágil de notificación y retirada de los contenidos infractores en internet), de la protección registral de la propiedad intelectual, y de la gestión colectiva de los derechos por asociaciones de titulares de derechos autorizadas y supervisadas por las Administraciones en los casos en que la gestión colectiva obligatoria aporta un valor añadido, como la reducción de los descuentos de administración en beneficio de titulares y usuarios de los derechos (piénsese, por ejemplo, en el derecho de comunicación pública, cuya gestión atomizada provocaría que el coste de dicha gestión superara al propio valor del derecho), coexistiendo con entidades empresariales que compitan para ofrecer una mejora de la administración de los $\triangleright$ 
derechos en los que esa gestión colectiva obligatoria no es necesaria.

Dos cuestiones deben ser tenidas en cuenta actualmente, en todo caso, en el diseño de esa política de respeto u observancia:

- En particular, las tecnologías digitales facilitan la transmisión y la posibilidad de reproducir toda información que exista en formato digital, incluidas las obras protegidas por derecho de autor. Ello exige una adaptación de la protección jurídica para no privarla de eficacia.

- Los modelos de difusión que no respetan las reglas de juego del derecho de autor compiten deslealmente en el mercado y pueden poner en riesgo la sostenibilidad y el crecimiento del sector de las industrias culturales.

\section{Relación entre protección de la propiedad intelectual y desarrollo económico, social y cultural}

La protección del derecho de autor y los derechos conexos cumple el doble objetivo de preservar y desarrollar la cultura y brindar un instrumento para proteger la explotación comercial de los bienes y servicios producidos por las industrias culturales y creativas contra la competencia desleal que suponen los modelos de negocio que no respetan estos derechos ni compensan el esfuerzo de la creación cultural, y además es una forma de asegurar la creatividad y la innovación, que beneficia al conjunto de la sociedad, más allá de la protección en sí misma, siendo la base para numerosos modelos de negocios que sin ella no existirían.

La forma en que se manifiesta esta protección está en el otorgamiento, por los derechos de propiedad intelectual, a sus titulares, de la facultad de impedir que terceras personas o empresas plagien, reproduzcan o comuniquen al público las creaciones de aquellos (libros, música, pintura, películas, programas informáticos, bases de datos, anuncios publicitarios, mapas, dibujos técnicos...) sin su autorización. Esto se complementa con el derecho a percibir una remuneración por consentir cualquier acto de explotación de las mismas.

También mantiene una cadena de valor de creación de riqueza, empleo cualificado y recaudación para la Hacienda Pública (que se traduce en la posibilidad del Estado de invertir en sanidad, educación, etc.).

\section{Objetivo empresarial: cuidar la propiedad intelectual de la empresa}

Algunos de los ejemplos de mayor éxito empresarial comenzaron siendo pymes, y supieron encontrar en los derechos de propiedad intelectual herramientas para la protección de sus creaciones e innovaciones (sectores de la moda, la joyería, el comercio minorista, la alimentación, etc.). En un entorno de evolución constante y cada vez más acelerado, estos mecanismos son fuente de riqueza y garantía de viabilidad empresarial a largo plazo.

Se calcula que el valor de las empresas en la actualidad descansa en buena medida en los activos intangibles (intangible assets), como el know-how, marcas, datos, etc., representando más del $80 \%$ de su valor, por lo que es necesario protegerlos. La propiedad intelectual constituye, en este contexto, un recurso clave de big data para el know-how y la inteligencia de mercados (marketing intelligence).

Adicionalmente, la propiedad intelectual repercute positivamente en el bienestar de los $D$ 
trabajadores (recientemente, con la elección, por la Organización Mundial de la Propiedad Intelectual -OMPI-, de la temática en torno a las pymes con ocasión del Día Mundial de la Propiedad Intelectual 2021, se puso de relieve que los trabajadores de las empresas que cuidan su propiedad intelectual gozan de mejores salarios, hasta de un $19 \%$ por encima de los de las empresas que no rentabilizan su propia propiedad intelectual y tienen dependencia de la de otras empresas).

\section{Objetivo gubernamental: cuidar la propiedad intelectual}

Aunque la actividad administrativa y de gobierno, en materia de derechos de autor y derechos conexos, es llevada a cabo conforme a un corpus técnico-jurídico integrado por la legislación y convenios internacionales vigentes en esta materia, enormemente complejo y cambiante, y que supone un instrumento esencial para la Administración General del Estado en relación con las grandes necesidades y oportunidades que representa este campo para el interés general de España, los Gobiernos y Administraciones deben tener siempre en cuenta que la cultura y los recursos que esta genera actúan como factor de desarrollo y sostenibilidad territorial. La diversificación, consolidación y mejora de la oferta cultural en el territorio es fundamental para avanzar en la cohesión social y un factor clave para el desarrollo económico a lo largo del territorio.

Por otra parte, la propiedad intelectual favorece el emprendimiento en casos que sin ella se verían minorizados (mujeres emprendedoras, empresas cuyo mercado son las personas LGBTI o los hablantes de lenguas no mayoritarias).
Y, por supuesto, la propiedad intelectual es un activo estratégico que crea riqueza y empleo de calidad, y garantiza la sostenibilidad de un sector económico vinculado a la sociedad de la información y con una gran potencialidad, especialmente en los territorios con industrias culturales arraigadas y con una lengua de comunicación internacional.

Una actuación gubernamental que cuide la propiedad intelectual como activo estratégico que favorezca el emprendimiento y el desarrollo debe pasar por:

- Una actualización constante de la normativa a las nuevas tecnologías. A este respecto, va a ser clave la culminación del procedimiento normativo para la aprobación de la futura ley sobre los derechos de propiedad intelectual en el Mercado Único Digital europeo, que ya se ha iniciado y que transpondrá al derecho interno español las antes citadas Directiva (UE) 2019/789 SatCab y Directiva (UE) 2019/790 de derechos de autor en el Mercado Único Digital (Directiva MUD). Debe recordarse que la Directiva MUD incluye medidas dirigidas a facilitar acceso a contenidos protegidos para ciudadanos y empresas (nuevos límites o excepciones a los derechos de propiedad intelectual, o uso de obras fuera de comercio por instituciones de patrimonio cultural), medidas de protección de publicaciones de prensa en usos en línea (nuevo derecho conexo para editores y autores de prensa) y medidas para corregir la brecha de valor (value gap, uso de contenidos protegidos por parte de prestadores de servicios para compartir contenidos en línea) y de remuneración justa para autores en contratos de $\triangleright$ 
cesión (nuevos derechos para autores, artistas e intérpretes).

Adicionalmente, está prevista la aprobación del nuevo Reglamento del Registro de la Propiedad Intelectual para adaptar este órgano a la nueva realidad digital y la modificación del Reglamento de funcionamiento de la Sección Segunda de la Comisión de Propiedad Intelectual, para facilitar la lucha contra las nuevas formas de vulneración de la propiedad intelectual en internet, e igualmente las actuaciones normativas necesarias de cara a la creación y regulación de la Oficina Española de Derechos de Propiedad Intelectual.

- El apoyo a la gestión colectiva de los derechos de propiedad intelectual y a su transformación digital. Los agentes intervinientes en el sistema de la protección y gestión de los derechos de propiedad intelectual deben desarrollar sus actividades en consonancia con las transformaciones y demandas de un sector cultural cada vez más digitalizado en toda su cadena de valor. Los derechos de propiedad intelectual constituyen el músculo de las industrias culturales y creativas, ya que son los que permiten su sostenimiento y servir de trampolín para la propia creación. Un sector cultural equilibrado es un sector cultural diverso y robusto. Hay que referir el proyecto, previsto en los ejercicios 2021 y 2022 en el marco del Plan de Recuperación, Transformación y Resiliencia, para el apoyo a los proyectos de digitalización de los operadores de gestión de derechos de propiedad intelectual (línea de ayudas en concurrencia competitiva dirigida a todos los operadores que realizan gestión colectiva de derechos de propiedad intelectual en España -entidades de gestión autorizadas por el Ministerio de Cultura y Deporte y operadores de gestión independientes-, que propone una inyección de ayuda económica de $15 \mathrm{mi}$ llones de euros entre 2021 y 2022).

El consumo de obras y productos culturales en el contexto digital ha hecho más complejo y más necesario que nunca el trabajo de documentación, recaudación y reparto. Tras la crisis de la COVID-19, los autores y demás titulares de derechos deben apoyarse hoy más que nunca en sus entidades y operadores de gestión para asegurarse una remuneración por el uso de sus obras. Para ello se ha propuesto esta línea de ayudas que cofinancie estos procesos de transformación digital para lograr una rápida adaptación de la gestión al entorno digital.

- La inversión para la transformación digital de las unidades administrativas con competencias en materia de propiedad intelectual. De la misma manera, los agentes públicos requieren de nuevas herramientas digitales que acompañen los diferentes procesos intervinientes, como el registro de las obras. El proyecto previsto al respecto en el marco del Plan de Recuperación, Transformación y Resiliencia propone una inyección de financiación de 1.255 .000 euros entre 2021 y 2023.

- El establecimiento de medios alternativos de resolución de controversias en el sector cultural. Desde los años sesenta del siglo pasado existe en toda Europa y en el mundo una tendencia a hacer intervenir a órganos de resolución de controversias para la solución de los $\triangleright$ 
conflictos que existen en el ámbito de los derechos de autor y derechos conexos. La Ley de Propiedad Intelectual de 1987 creó en España la entonces Comisión Arbitral de la Propiedad Intelectual, que desde entonces ha sido el instrumento de resolución de controversias en esta materia, al margen de los instrumentos del ámbito privado, adscrita al Ministerio de Cultura, y que no ha hecho sino ir ampliando su campo de actuación y el tipo de procedimientos en los que es competente.

La actual Sección Primera de la Comisión de Propiedad Intelectual (artículos 193 y 194 del TRLPI) se caracteriza por ser un órgano colegiado de ámbito nacional, para el ejercicio de las funciones de mediación, arbitraje, determinación de tarifas y control en los supuestos previstos legalmente. Asimismo ejerce funciones de asesoramiento sobre los asuntos de su competencia que le sean consultados por el Ministerio de Cultura y Deporte.

Ya está previsto, además, que, con la transposición de la referida Directiva (UE) 2019/790 MUD, los Estados miembros de la Unión Europea deban garantizar un mecanismo extrajudicial de reclamación y recurso ágil y eficaz en el ámbito del uso de contenidos protegidos por parte de prestadores de servicios para compartir contenidos en línea, e igualmente un procedimiento alternativo de resolución de litigios de carácter voluntario en relación con las obligaciones de transparencia en la gestión de los derechos de propiedad intelectual en el ámbito de las plataformas en línea.

- La lucha contra la vulneración de los derechos de propiedad intelectual. Las conductas infractoras de estos derechos tienen un impacto económico muy elevado que, además, no se circunscribe a la valoración del perjuicio generado por la conducta vulneradora en particular, sino por la constricción directa que genera el conjunto de actividades delictivas en la actividad económica legal de las industrias culturales y creativas.

Las características de estas conductas las convierten en una alternativa, auténtica competencia desleal, de la actividad económica de industrias culturales y creativas, lo que supone que su existencia tenga un impacto negativo en las actividades de carácter lícito.

Además, esa particular configuración de la vulneración de los derechos de propiedad intelectual, en tanto en cuanto afecta directamente a sectores económicos, sustrayendo actividad de los mismos, supone que el impacto económico no solo se circunscriba a intereses jurídico-privados, sino también que afecte a los intereses públicos: se pierde tejido industrial, empleos, cotizaciones a la Seguridad Social, tributos, salarios y poder adquisitivo de los ciudadanos, con la consecuente contracción del consumo, la economía y la competitividad. La pérdida de ingresos en las arcas públicas repercute negativamente en servicios sociales, sanitarios, educativos, etc.

Según datos del Observatorio de Piratería y Hábitos de Consumo Digitales, solo en 2020, en España se accedió a 5.239 millones de contenidos que vulneraban derechos de propiedad intelectual. El vaIor de dichos contenidos es de 30.892 millones de euros y el perjuicio para el sector alcanzó los 2.416 millones de $\triangleright$ 
euros. Además, el Estado —arcas públicas- habría dejado de ingresar 682 millones de euros durante 2020, una cifra que se eleva a los 5.340 millones desde 2012, y se podrían haber creado más de 130.000 puestos de trabajo directos e indirectos en España.

- La cooperación internacional, imprescindible en la medida en que el acceso a los contenidos digitales es claramente global y transnacional.

- Finalmente, la sensibilización de la ciudadanía en los medios y en el entorno escolar.

Debe señalarse que las reformas e inversiones relacionadas con la actualización de la normativa en materia de propiedad intelectual a las nuevas tecnologías, el apoyo de la gestión colectiva de estos derechos y de su transformación digital, y la inversión para la transformación digital de las unidades administrativas con competencias en materia de propiedad intelectual se encuentran en el Componente 24 del Plan de Recuperación, Transformación y Resiliencia, y parten de la premisa de que la tecnología digital ha planteado un nuevo escenario para las industrias culturales y creativas, permitiendo el desarrollo de nuevos modelos de negocio, nuevos productos culturales, nuevos formatos artísticos y espacios de difusión cultural, así como la generación de nuevos públicos necesarios para fomentar un mayor desarrollo del sector cultural. La transición digital y la digitalización son una línea de actuación estratégica del sector de cara a su revalorización y sostenibilidad futura. Asimismo, debe abordarse el reto de la comunicación y la accesibilidad, permitiendo aumentar el impacto social y económico de toda actividad cultural.
Dichas reformas e inversiones jugarán un papel esencial en los tres próximos ejercicios para que el sector económico cultural español pueda hacer frente a los desafíos que debe abordar para fomentar su crecimiento, innovación, internacionalización, formación y una verdadera transformación digital.

\section{El futuro. La regulación de la propiedad intelectual en un mundo global y digital}

Los motores que en el futuro van a seguir provocando sucesivas reformas y adaptaciones de la normativa de propiedad intelectual van a ser una continuación de los que nos han acompañado en los últimos treinta años:

- Desarrollo cada vez más vertiginoso de las nuevas tecnologías digitales, incluyendo la inteligencia artificial (IA), que impactan en la reproducción y difusión de los contenidos culturales y en los hábitos de consumo.

- Continuación en el camino de la integración europea y en el mercado interior (licencias multiterritoriales, portabilidad de contenidos, limitación del geobloqueo, etc.), que antes o después hará ceder el principio de territorialidad nacional por una nueva territorialidad europea de los derechos de propiedad intelectual y de su gestión, siendo el objetivo que esa evolución disfrute de una transición ordenada que no ponga en riesgo la diversidad cultural y la financiación de las industrias culturales y creativas, permitiendo a Europa competir en un mundo global. 
En el ámbito internacional, hoy la carrera contra reloj está en las instituciones de la Unión Europea, para garantizar una protección uniforme de los derechos de propiedad intelectual en el funcionamiento del mercado interior y en toda la Unión, como señala desde 2007 el artículo 118 del Tratado de Funcionamiento de la Unión Europea.

En estos momentos en que asistimos a una constante puesta al día de la legislación sobre derechos de propiedad intelectual, los Gobiernos de los Estados miembros de la UE van incorporando a los derechos internos las dos directivas comunitarias aprobadas en 2019, e intentan alcanzar a la realidad de la difusión de los contenidos en la sociedad de la información, cuya actual tendencia es el incremento del acceso en streaming y la disminución de la clásica realización de copias para uso privado (esta disminución de la copia privada, no obstante, aplicable a los últimos ejercicios, se invirtió durante 2020).

Uno de los focos del debate está siendo la adaptación de los límites a los derechos de propiedad intelectual a la era digital, y en España hemos sido pioneros en esta adaptación en lo referido a los límites de cita y reseña e ilustración con fines educativos o de investigación científica: debe destacarse que en 2014 el legislador español actualizó para el entorno digital el régimen aplicable a las reseñas realizadas por servicios electrónicos de agregación de contenidos, una línea que fue recogida por la Comisión Europea en la entonces propuesta de directiva de derechos de autor en el Mercado Único Digital, hoy Directiva (UE) 790/2019.

En dicha directiva y en todos los instrumentos que buscan armonizar un Mercado Único Digital europeo de los derechos de propiedad intelectual debe ser la conclusión sobre el futuro de la regulación: conjugar el valor estratégico global de la propiedad intelectual con las nuevas oportunidades que ofrecen tanto la sociedad de la información como los nuevos canales y sistemas de creación, comunicación y distribución.

Finalmente, es imprescindible una referencia a la próxima regulación, que deberá hacerse en el ámbito europeo, de los derechos de autor de los que sean objeto las obras generadas por inteligencia artificial y que debería garantizar que la persona física que inicie el proceso de creación, con independencia del autor del algoritmo utilizado, sea considerado el autor de las obras generadas con IA cuando estas puedan considerarse creaciones originales literarias, artísticas o científicas, y que las personas jurídicas puedan beneficiarse de esta consideración de autoría en los casos expresamente previstos en la normativa vigente en materia de derechos de autor.

\section{Bibliografía}

Convenio de Berna para la protección de las obras literarias y artísticas, de 9 de septiembre de 1886, revisado en Berlín el 13 de noviembre de 1908 y en Roma el 2 de junio de 1928. Gaceta de Madrid, n. 115 , de 25 de abril de 1933, pp. 618 a 623. https://www.boe.es/buscar/doc. php?id=BOE-A-1933-41613

Directiva 2001/29/CE del Parlamento Europeo y del Consejo, de 22 de mayo de 2001, relativa a la armonización de determinados aspectos de los derechos de autor y derechos afines a los derechos de autor en la sociedad de la información. Diario Oficial de las Comunidades Europeas. https:// www.boe.es/doue/2001/167/L00010-00019.pdf

Directiva (UE) 2019/789 del Parlamento Europeo y del Consejo, de 17 de abril de 2019, por la que se establecen normas sobre el ejercicio de los derechos de autor y derechos afines aplicables a determinadas transmisiones en línea de los organismos de radiodifusión y a las retransmisiones $D$ 


\section{LA PROPIEDAD INTELECTUAL COMO HERRAMIENTA DE DESARROLLO ECONÓMICO, SOCIAL...}

de programas de radio y televisión. Diario Oficial de la Unión Europea. https://www.boe.es/ doue/2019/130/L00082-00091.pdf

Directiva (UE) 2019/790 del Parlamento Europeo y del Consejo, de 17 de abril de 2019, sobre los derechos de autor y derechos afines en el mercado único digital. Diario Oficial de la Unión Europea. https://www.boe.es/doue/2019/130/ L00092-00125.pdf

Gobierno de España (2021). Componente 24. Revalorización de la Industria Cultural. Plan de Recuperación, Transformación y Resiliencia. https:// www.lamoncloa.gob.es/temas/fondos-recuperacion/Documents/05052021-Componente24.pdf

Real Decreto Legislativo 1/1996, de 12 de abril, por el que se aprueba el texto refundido de la Ley de
Propiedad Intelectual, regularizando, aclarando y armonizando las disposiciones legales vigentes sobre la materia. Boletín Oficial del Estado, n. .97 , de 22 de abril de 1996, pp. 14369 a14396. https://www.boe.es/eli/es/rdlg/1996/04/ $12 / 1 /$ con

Real Decreto 1889/2011, de 30 de diciembre, por el que se regula el funcionamiento de la Comisión de Propiedad Intelectual. Boletín Oficial del Estado, n.․ 315, de 31 de diciembre de 2011. https://boe.es/buscar/act.php?id=BOE-A-201120652

Versión consolidada del Tratado de funcionamiento de la Unión Europea. Diario Oficial de la Unión Europea, de 10 de marzo de 2010, pp. 47 a 99. https://www.boe.es/doue/2010/083/Z0004700199.pdf 
